\title{
Utilisation of Antenatal Services at the Provincial Hospital, Mongomo, Guinea Equatoria
}

\author{
AAG Jimoh
}

\begin{abstract}
This prospective study was carried out to evaluate the utilisation of antenatal care at the Provincial Specialist Hospital, Mongomo, Guinea Equatoria, paying close attention to the confounding factors affecting effective antenatal care (ANC) delivery. Information was elicited from 200 pregnant women attending the antenatal clinic using a questionnaire. Previous antenatal clinic attendance was high (92.5\%). However, with increasing gestation, the percentage of those who never had antenatal care increased. Poor ANC attendance is associated with more abortions and poor obstetric performance. Higher levels of education generally improved ANC attendance, particularly early booking for ANC. Hospital workers, husbands and parents were the greatest influence on ANC attendance. Universal education of the women, improved health education, community involvement and integration of traditional birth attendants (TBAs) are significant suggestions made by the patients for improving the delivery of antenatal care. (Afr J Reprod Health 2003; 7[3]: 49-54)
\end{abstract}

\section{RÉSUMÉ}

Utilisation des services de soins prénatals à l'hôpital provincial de Mongomo, Guinée Equatoriale. Cette étude prospective a été menée pour évaluer l'utilisation des services de soins prénatals à l'Hôpital Spécialisé Provincial à Mongomo en Guinée Equatoriale, en mettant l'accent sur les facteurs déconcertant qui affectent les prestations des soins prénatals (SP) efficaces. Nous avons recueilli des renseignements à l'aide des questionnaires au sein des 200 femmes enceintes qui fréquentaient des consultations prénatales. La fréquentation ultérieure de la consultation prénatale était élevé (92,5\%). Pourtant, avec l'augmentation de la gestation, il y a eu une augmentation dans le pourcentage de celles qui n'avaient jamais eu des soins prénatals. Une faible fréequentation de la consultation prénatale est lié à des avortements supplémentaires et à des performances obstétriques médiocres. Des niveaux élevés d'éducation ont généralement amélioré la fréquentation à la consultation prénatale, surtout quand il s'agit des s'inscrire tôt pour la consultation prénatale. Les plus grandes influences sur la consultation prénatale était le personnel hospitalier, les maris et les parents. Une éducation universelle des femmes, une meilleure éducation de la santé, l'implication de la communauté et l'intégration des sages-femmes traditionnelles (SFT) sont parmi les propositions importantes données par les patientes pour améliorer la présentation des soins prénatals. (Rev Afr Santé Reprod 2003; 7[3]: 49-54)

KEY WorDs: ANC, abortion, Guinea Equatoria

Correspondence: Dr A.A.G. Jimoh, Department of Obstetrics and Gynaecology, University of Ilorin Teaching

Hospital, Ilorin, Nigeria.E-mail:jimohaag@ifrance.com 


\section{Introduction}

Antenatal care in pregnant women has been shown by various authors to improve maternal health, thereby reducing maternal and infant morbidity and mortality. ${ }^{1-5}$

The specialist hospital in Mongomo, Guinea Equatoria, is a secondary level health care institution with patients coming from villages within the province and the neighbouring Republic of Gabon. Guinea Equatoria has a maternal mortality rate of 8.5 per 1000 and infant mortality rate of 128 per 1000 , one of the highest in the world. ${ }^{1}$ Antenatal care services in the hospital are not based purely on referral system, most patients are accepted for antenatal care on registration in the hospital. Many patients who are 'obstetric risk patients' are also sent by the puestos de salud (primary health care centres).

A cursory look revealed that a lot of the women attending antenatal care book late and many times do not deliver in hospital even after attending antenatal care. With this realisation and the fact that health care delivery, particularly maternity services, in Guinea Equatoria are faced with a lot of problems, this study was carried out to evaluate the utilisation of available antenatal services at the Mongomo Specialist Hospital, paying close attention to the factors affecting effective antenatal care delivery.

\section{Materials and Methods}

A prospective study on consecutive 200 pregnant women attending the antenatal clinic of the Mongomo Specialist Hospital was carried out between April and July 1997 using a 20-item questionnaire.

Since the official language in the country is Spanish, the questionnaire was written in Spanish language. A pre-test was done on about 20 women (not included in the study), noting proper interpretation of the questions in Fang language (spoken by the majority of the study population), ensuring that the same two midwives versed in this language who applied the pre-test also filled the questionnaires.

\section{Results}

The ages of the patients seen at the antenatal clinic ranged from 13 to 44 years with a mean of $24.85 \pm$ 2.36 years. Ten $(5 \%)$ patients were below 15 years old, $75(37.5 \%)$ were teenagers, while elderly women (> 35years) formed $15 \%$ of the patients (Table 1).

One hundred and ninety two $(96 \%)$ women were from the Fang tribe, $2(1 \%)$ from Bubi tribe, while others, including foreigners, were $6(3 \%)$. Majority (98\%) of the patients were Christians, mainly Catholics $(90 \%)$. Some $67.5 \%$ of the patients resided in Mongomo District while $20(10 \%)$ came from Oyem town (Gabon Republic). About a third of the women attending antenatal clinic travelled more than $30 \mathrm{~km}$ to the hospital. Only $38(19 \%)$ of the patients were married. Farmers $(13.5 \%)$ and policemen $(13.5 \%)$ formed the bulk of their husbands. Almost a quarter of the patients had no formal education, $49 \%$ had primary education, while only $1.5 \%$ had post-secondary education.

\section{Table 1 Distribution of Patients according to Age}

\begin{tabular}{lcr}
\hline Age (years) & Frequency & (\%) \\
\hline$\leq 15$ & 10 & 5.0 \\
$15-19$ & 66 & 33.0 \\
$20-24$ & 24 & 12.0 \\
$25-29$ & 40 & 20.0 \\
$30-34$ & 30 & 15.0 \\
$35-39$ & 5 & 2.5 \\
$>40$ & 25 & 12.5 \\
Total & 200 & 100.0 \\
\hline
\end{tabular}

Table 2 shows that $36 \%$ of the patients had previous abortions, with the highest number seen amongst the grandmultigravidae. Previous antenatal care attendance amongst $92.5 \%$ of the patients was quite impressive. However, with increasing gestation, the percentage of those who never had ANC increased (Table 3). It is also clear that poor ANC attendance is associated with more abortions and poor obstetric performance. 
Table 2

Patient Distribution According to Gravidity and Previous Abortion

\begin{tabular}{lrrcr}
\hline Gravida & No. & $\mathbf{( \% )}$ & Previous abortion & $\mathbf{( \% )}$ \\
\hline 1 & 47 & 23.5 & - & - \\
2 & 10 & 5.0 & 2 & 20.0 \\
3 & 32 & 16.0 & 10 & 32.0 \\
4 & 18 & 9.0 & 8 & 44.4 \\
5 & 15 & 7.5 & 8 & 53.3 \\
$>5$ & 78 & 39.0 & 44 & 56.3 \\
\hline Total & 200 & 100 & 72 & 36.0 \\
\hline
\end{tabular}

Table 3 Comparison between Previous ANC Attendance and Gravidity

\begin{tabular}{|c|c|c|c|c|c|c|}
\hline \multirow[t]{2}{*}{ Gravidity } & \multirow[b]{2}{*}{ Never } & \multirow[b]{2}{*}{$\%$} & \multicolumn{2}{|c|}{ ANC attendance } & \multirow[t]{2}{*}{ Total } & \multirow[t]{2}{*}{$\%$} \\
\hline & & & Yes & $\%$ & & \\
\hline 1 & - & - & 47 & 100.0 & 47 & 23.5 \\
\hline 2 & - & - & 10 & 100.0 & 10 & 5.0 \\
\hline 3 & 2 & 6.3 & 30 & 93.8 & 32 & 16.0 \\
\hline 4 & 2 & 11.1 & 16 & 88.9 & 18 & 9.0 \\
\hline 5 & 3 & 20.0 & 12 & 80.0 & 15 & 7.5 \\
\hline$>5$ & 8 & 10.3 & 70 & 89.8 & 78 & 39.0 \\
\hline Total & 15 & 57.7 & 185 & 92.5 & 200 & 100.0 \\
\hline
\end{tabular}

Higher levels of education improved ANC attendance in general and early booking for ANC care in particular (Table 4). From the study, hospital workers (50.73\%), husbands (14.71\%) and parents $(13.9 \%)$ had a lot of influence on ANC attendance whilst farming season (18.97\%), safe delivery and treatment $(13.05 \%)$, conveniences $(10.93 \%)$, reduction in number of antenatal visits $(9.71 \%)$ were the factors that mostly influenced the time of registration for ANC care. Poor obstetric history, previous obstetric complications and advice by the ANC staff made more women to book early, while reduction in the number of visits, traditional practice and distance were responsible factors for registration in the third trimester. Most of the women $(93 \%)$ believed that they derived benefits from the antenatal care rendered and $98 \%$ of them considered the ANC care offered as acceptable (Table 5).

Traditional birth attendants (TBAs) were believed to be better than orthodox practitioners (in some respects) by a third of these patients, nearer to them $(39 \%)$ and have certain spiritual powers $(29 \%)$. This is hardly surprising in view of the fact that most women still compliment ANC services with those offered by the traditional healers and TBAs. The present arrangements whereby ANC clinics are held on Mondays (64\%), Wednesdays (48\%) and Fridays $(44 \%)$ is considered acceptable, as most women have adjusted their daily activities to suit this arrangement. 
Table $4 \quad$ Relationship between Level of Education and ANC Attendance

\begin{tabular}{lcccccccr}
\hline $\begin{array}{l}\text { Level of } \\
\text { education }\end{array}$ & $\begin{array}{c}\text { 1st } \\
\text { trimester }\end{array}$ & $\%$ & $\begin{array}{c}\text { 2nd } \\
\text { trimester }\end{array}$ & $\begin{array}{l}\text { 3rd } \\
\text { trimester }\end{array}$ & Total & $\%$ \\
\hline None & 2 & 4.2 & 16 & 33.3 & 30 & 62.5 & 48 & 24.0 \\
Arabic & - & - & 1 & 25.0 & 3 & 75.0 & 4 & 2.0 \\
Primary & 18 & 18.4 & 32 & 32.7 & 48 & 49.0 & 98 & 49.0 \\
Post primary & 12 & 25.5 & 25 & 53.2 & 10 & 21.3 & 47 & 23.5 \\
Post secondary & 3 & 100.0 & - & - & - & - & 3 & 1.5 \\
\hline Total & 35 & 17.5 & 74 & 37.0 & 91 & 45.5 & 200 & 100 \\
\hline
\end{tabular}

Table 5 Patients' Perception of Quality of Antenatal Care Offered

\begin{tabular}{|c|c|c|c|c|c|c|c|c|c|c|c|}
\hline Gravidity & Poor & Fair & $\%$ & Good & $\%$ & V. good & $\%$ & Excellent & $\%$ & Total & $\%$ \\
\hline Primigravida & - & 1 & 2.1 & 22 & 46.8 & 23 & 48.9 & 1 & 2.1 & 47 & 23.5 \\
\hline Multigravida & - & 2 & 2.7 & 28 & 37.3 & 42 & 56.0 & 3 & 4.0 & 75 & 37.5 \\
\hline $\mathrm{G} /$ multigravida & - & 1 & 1.3 & 32 & 41.0 & 41 & 52.6 & 4 & 5.1 & 78 & 39.0 \\
\hline Total & - & 4 & 2.0 & 82 & 41.0 & 106 & 53.0 & 8 & 4.0 & 200 & 100.0 \\
\hline
\end{tabular}

The fact that $41 \%$ of these patients solicited for obligatory ANC care to all women showed the level of awareness about the necessity of ANC care. Six $(3 \%)$ women advocated community involvement, which is very commendable even though the percentage is small.

\section{Discussion}

It is evident from this study that teenagers formed $37.5 \%$ of the study group. This is lower than the number of pregnant women in a Zaria study where more than two thirds were teenagers, ${ }^{3,4}$ but higher than an earlier study by the author from Nigeria. ${ }^{2}$ It is also similar to findings from other parts of $\mathrm{Africa}^{7}$ where teenage pregnancy accounts for $25-40 \%$ of the pregnant population. Most of these teenage pregnant women were single, school dropouts, unsupported and tended to have obstetric complications in pregnancy and during labour. ${ }^{8-11}$
Most of the women $(80 \%)$ coming for antenatal care were either unmarried or have been divorced. The traditional custom surrounding marriage amongst the Fang makes it imperative for the prospective husband to pay a huge sum of money for dowry and other sundry expenses associated with the marriage ceremony. Therefore, most men shy away from the marriage institution or at best have live-in-lovers. ${ }^{6}$ Unsupported pregnant women have been shown to have poorer ability to utilise available antenatal care services. ${ }^{2-4,11,12}$ Hence, in an environment where the antenatal services rendered are sub-optimal, the picture for such women are gloomy indeed.

The value of formal education on antenatal care attendance have been revealed in this study. More women who had formal education tended to attend antenatal care clinic earlier and were more likely to follow instructions given by the attending doctor or midwife. The higher the 
formal education a woman had, the less likely she was to book late in pregnancy.,

The number of patients with previous abortions increased steadily with gravidity. However, there was a very sharp increase in the grandmultipara with previous abortions - this could be partly explained by the fact that most of the patients were older with increased risk of congenital malformations, poorer previous antenatal care attendance in this group of patients and probably poor nutritional reserves from repeated childbirths. ${ }^{4,5}$ The poor antenatal care attendance could also be attributed to over-confidence on the part of these grandmultiparas, as they are 'experienced' in matters relating to pregnancy such that many times they tend to book late, if they do book at all., This is especially so when viewed against the background that about one third of the women attending antenatal clinic had to travel more than $30 \mathrm{~km}$ to attend the clinic. Grandmultiparas are also at risk of abortions because of age-related fetal genetic malformations, maternal hypertensive diseases, maternal diabetes and other chronic illnesses.

Hospital workers $(50.73 \%)$, husbands (19\%) and parents $(13.97 \%)$ were the greatest influences on antenatal care attendance. In this study, all the married women $(19 \%)$ said their husbands were a strong influence on their antenatal care utilisation, thus, any attempt to improve ANC attendance has to take the men into consideration. The overbearing influence of the men tended to affect breastfeeding practices, susceptibility to HIV/ AIDS amongst women ${ }^{14}$ and contraceptive choices as well as antenatal care utilisation. ${ }^{15}$

The farming season, safe delivery and treatment, convenience and reduction in the number of antenatal visits were the factors that mostly determined the time of registration for antenatal care. Women with poor obstetric history and complications tend to book early irrespective of the level of education. Those who registered late were mostly grandmultiparous women who often felt confident that they do not have obstetric problems and are experienced in childbearing. For a third of the women, they had to travel more than $30 \mathrm{~km}$ to the hospital for antenatal care.
This is clearly unacceptable in view of the enormous problems encountered by these women in getting trans-portation, they sometimes have to travel in heavily loaded trucks and minibuses. ${ }^{5}$ Many of these women face untold hardships even when they come to Mongomo since the vehicle only goes back to the village a day or two after arrival. This has been clearly shown by other studies as well to affect antenatal utilisation and subsequent delivery in hospital. ${ }^{13-15}$

It is gratifying to note that many women are still of the opinion that antenatal care services have been beneficial to them and have made useful suggestions to improve the level of ANC. Even though improved health education, health visits and community involvement were least suggested, they are more likely to produce better results in terms of antenatal care attendance. According to Ademuwagun, ${ }^{17}$ health education can only be meaningful to the traditionally inclined people if it is tied to the intrinsic values of the people themselves. In this respect, health education can only improve antenatal care utilisation if the communities at different levels are involved in motivation and information dissemination with active involvement of the men folk. This can be supplemented by home visits by the various health workers. The training being given to the TBAs at the hospital will be more meaningful if they are aware that they are not trained to be doctors, hence with certain limitations. They should quickly refer 'at-risk' patients to the hospital for proper evaluation and treatment.

Many of these patients still patronise TBAs because they are believed to be nearer, possess special powers and cheaper to consult. The TBAs need to be further integrated into the maternity services if we are to witness improved attendance in antenatal care services and improve-ment in the scourge of maternal and infant mortalities as presently experienced in this country.

\section{Acknowledgements}

The author is grateful to the two matrons at the maternity wing of the hospital, Signora Armanda Ada Nguema and Signora Carlota Nchama Sima who helped with the pre-tests and application of the 
questionnaires. Our thanks also go to Mr. J. S. Okoji of the Department of Obstetrics and Gynaecology, University of Ilorin Teaching Hospital, Ilorin, Nigeria, for his secretarial assistance.

\section{REFERENCES}

1. UNICEF. State of the world's children. 1988, 178.

2. Jimoh AAG. Utilization of antenatal services in Koko town, Sokoto State, Nigeria. Nig J Med (In Press).

3. Harrison KA. Maternal mortality in Zaria, Nigeria. In: Obstetrics and Gynaecology in Developing Countries. Proceedings of an international conference organised by Society of Gynaecology and Obstetrics of Nigeria, Ibadan, 16-23 October 1977, 274-276.

4. Harrison KA. Maternal mortality - a sharper focus of a major issue of our time. Trop J Obstet Gynaecol 1988; 1(1): 9-13.

5. Ekwempu CC. The influence of antenatal care on pregnancy outcome. Trop J Obstet Gynaecol 1988; 1(1): 67-71.

6. Jimoh AAG. Biosociocultural factors in the reproductive health amongst women in Mongomo, Guinea Equatoria. C Afr J Med (In Press).

7. Gyepi-Garbrah B (Ed.). Adolescent Fertility in SubSabaran Africa: An Overview. The Pathfinder Fund, 1985.
8. Adetoro OO and Ekwerekwu FO. Maternal mortality at Ilorin, Nigeria. Trop J Obstet Gynaecol 1988; 1(1): 18-22.

9. Editorial. Obstetric fistula. Lancet 1981; June 27: 1402-1403.

10. Effiong EI and Banjoko MO. The obstetric performance and Nigerian primigravidae aged 16 and under. Br J Obstet Gynaecol 82: 223-228.

11. Akindele F and Roberts OA. Maternal mortality at the University College Hospital, Ibadan. A ten-year review. Proceedings of the 5 th International Congress of SOGON, Benin City, Nigeria, 25th to 28th November 1998.

12. Birch D. Schoolgirl pregnancies. In: John Studd (Ed.). Progress in Obstetrics and Gynaecology. Volume 7. 1993, 75-90.

13. Fagbule D and Adedoyin MA. Knowledge, beliefs and attitudes towards breastfeeding in Ilorin. W Afr J Med 1987; 6(2): 88-89.

14. UNAIDS and Economic Commission for Africa (ECA). AIDS in Africa - country by country. African Development Forum. Geneva: WHO, October 2000.

15. Chika-Ezeh A. The influence of spouses over each other's contraceptive attitudes in Ghana. Stud Fam Plann 1993; 24: 123-174.

16. Johnson TRB. Infant mortality: patterns, parallel and ironies. Int J Gynaecol Obstet 1993; 40: 195-197.

17. Ademuwagun ZA. 'Alafia' - the Yoruba concept of health (implications for health education). Inter J Health Edu 1978; XXI(2): 89-97. 